\title{
Heavy metal extraction by a counter-flow moving bed reactor
}

\author{
Azza H. Ali, M. Abdelaziz, H. F. Elbakhshawangy, Sameh H. Othman* \\ Nuclear Research Center, Atomic Energy Authority, Cairo, Egypt; ${ }^{*}$ Corresponding Author: othman sameh@yahoo.com
}

Received 21 August 2012; revised 25 September 2012; accepted 5 October 2012

\section{ABSTRACT}

In the current study, the extraction of heavy metal ions $\left(\mathrm{Zn}^{2+}, \mathrm{Cu}^{2+}\right.$ and $\left.\mathrm{Cd}^{2+}\right)$ is suggested to be achieved by a counter-flow moving bed reactor. The studies are made at high $\left(1 \times 10^{-2} \mathrm{M}\right)$ and low $\left(1 \times 10^{-4} \mathrm{M}\right)$ initial concentrations of the heavy metal ions. Theoretical and experimental studies are made on the extraction of the metal ions with impregnated Amberlite resins, prepared by sorption of an organic extractant into the resin. The study suggests structural, kinetic and hydrodynamic parameters that shall be investigated prior to the design of a moving bed reactor. The effect of these parameters on the adsorption extent is theoretically investigated through the proposed model. Analyses of the experimentally estimated external, internal and chemical rate parameters show that the process is controlled by chemical reaction in both concentrations as the chemical reaction rate parameter is significantly smaller than both the internal and the external diffusion rate parameters.

Keywords: Chemical Reactors; Diffusion; Mathematical Modeling; Hydrodynamic Parameters; Heavy Metals; Amberlite Resins

\section{INTRODUCTION}

The integration of reaction and separation of the corresponding products in solid-liquid reactors allows, in addition to obvious savings in equipment costs, significant improvements in the process performance. Typical reactor examples of that type include moving bed reactors.

The solid-liquid contact in a moving bed reactor might occur, either in a co-current or a counter-current mode. Common examples of counter-current moving bed are inclined and vertical kilns and transport reactors. Similar to other fluid-solid reactors, the global kinetics of the reactor is determined by mass transfer from the bulk fluid to the interior of the solid phase and/or by the chemical reaction. Generally, the internal mass transfer inside the solid particle offers much greater resistance than other steps [1-5], so that it can be considered as the rate-determining step.

Selective separation of metal ions from aqueous solutions might be carried out through solvent-impregnated resin (SIR) [6-8], which efficiently extracts solute ions from dilute liquors. This resin type, in specific, has a high distribution ratio and a high selectivity for extractants dissolved in a liquid organic phase. It also exhibits strong affinity for the polymeric matrix though behaving as if it were in the liquid state [8-10]. Some studies showed that the impregnated resins, prepared by the adsorption of a bi-functional extractant onto large surface macroporous supports of Amberlite XAD2, are successfully used for the extraction of $\mathrm{Zn}^{2+}, \mathrm{Cu}^{2+}$ and $\mathrm{Cd}^{2+}$ ions $[11,12]$. Former studies were devoted to the impregnation processes, the physico-chemical characterization of resins, the description of the extraction reactions, or the selectivity patterns. However, the application of these systems in a fixed column or fluidized bed technology requires information of the equilibrium and kinetics of the metal extraction processes and the hydraulic operating behaviour. In the present study a mathematical model describing the behaviour of a counter-flow moving-bed reactor is proposed analogous to those formerly suggested for a batch and a fixed bed reactor [3,5]. This study may help in suggesting proper design and operation conditions in order to scale-up the overall process.

\section{EXPERIMENTAL}

\subsection{Reagents}

The chemicals used in this study are of analytical grade (Merck A.R. grade) and are used as received. Stock solutions of $\mathrm{Zn}(\mathrm{II}), \mathrm{Cu}(\mathrm{II})$ and $\mathrm{Cd}(\mathrm{II})(1 \mathrm{~g} / \mathrm{L})$ are prepared by dissolving the corresponding nitrate salt in water. The used Amberlite XAD-2 resin is supplied by Rohm and Haas with $0.3-0.9 \mathrm{~mm}$ size. O-methyl-dihexyl-phosphine-oxide-O'-hexyl-2-ethyl phosphoric acid 
(HL) with purity higher than $98 \%$ is used. The SIR resins are prepared as previously described $[11,12]$.

\subsection{Sorption Kinetics}

In the study the shallow bed technique on a micro scale is used where an aqueous metal solution is passed at a high flow-rate through a micro column of the resin bed [12-15]. The flow of the metal solution is stopped and the resin is washed with water and the resin compositions are analyzed to provide data about metal concentration as function of time. Micro columns around 2.5 $\mathrm{mm}$ depth are used and the employed flow-rate is $0.2 \mathrm{~L} / \mathrm{h}$. The $\mathrm{pH}$ of the metal solutions is maintained around 5 by adding $\mathrm{NaOH}$. All kinetic measurements are carried out at room temperature.

The metal ions concentrations are determined by elution using $0.2 \mathrm{M}$ hydrochloric acid solution. After dilution, the metal ions are analyzed by inductively atomic emission spectro-photometry using an ICP-AE JY-138 Ultratrace. The metal ions concentrations results are expressed as $\mathrm{mol} / \mathrm{kg}$ of dry SIR.

\section{MODEL DEVELOPMENT}

The sorption of metal ions on solvent impregnated resin in a counter flow moving bed reactor can be considered analogous to fluid-solid noncatalytic reactions. Such a reaction occurs by the adsorption of the fluid reactant at an active site on the solid followed by a chemical reaction involving the adsorbate ion and the solid reactant. In a former study of S. Othman et al. [3] the diffusion rate, expressed as the number of moles adsorbed $(N)$ per unit time $(t)$ per particle, was suggested to be proportional to $\mathrm{e}^{-K_{D^{t}}}$, where $K_{D}$ is a diffusion parameter with a dimension of $\mathrm{s}^{-1}$. Two categories of diffusion parameters were discriminated; external diffusion parameter, which describes the diffusion through the aqueous boundary layer to the outermost resin layer $\left(K_{D_{1}}\right)$, and diffusion through the adsorbed layers $\left(K_{D_{2}}\right)$. As the adsorption kinetics is largely limited by the internal diffusion step [3,5], $K_{D_{1}}$ is likely found to be greater than $K_{D_{2}}$. Accordingly, the following two diffusion-type equations were proposed [3].

$$
\begin{gathered}
\frac{\mathrm{d} N}{\mathrm{~d} t}=4 \pi r_{b}^{2} K_{D_{1}} b \mathrm{e}^{-K_{D_{1}} t} \\
\frac{\mathrm{d} N}{\mathrm{~d} t}=4 \pi\left(r_{b}^{2}-r^{2}\right) K_{D_{2}} b \mathrm{e}^{-K_{D_{2}} t}
\end{gathered}
$$

where $N$ is the number of moles of product formed per unit time $(t)$ per particle, $r_{b}$ is the radius of the boundary layer, and $b\left(\mathrm{~mole} / \mathrm{m}^{2}\right)$ signifies the number of active sites available per unit surface area.

A third equation due to chemical reaction considering a pseudo-first order rate equation was also proposed [3, 5].

$$
\frac{\mathrm{d} N}{\mathrm{~d} t}=4 \pi\left(r_{b}^{2}-r^{2}\right) K_{1}\left(q_{e}-q\right)
$$

where $K_{1}\left(\mathrm{~kg} \cdot \mathrm{m}^{-2} \cdot \mathrm{s}^{-1}\right)$ is the chemical reaction rate parameter. The constant $q_{e}(\mathrm{~mol} / \mathrm{kg})$ is the equilibrium concentration of the product; i.e. the concentration of metal ion at the end of the moving bed reactor and $q$ $(\mathrm{mol} / \mathrm{kg})$ is the concentration of metal ion per unit mass of resin along the reactor height.

By applying steady state approximation, the two diffusion equations were equated resulting in a relation giving the variation of the un-reacted core radius in terms of time. Substituting this relation in the chemical reaction equation gives the following relation $[3,5]$.

$$
\frac{\mathrm{d} N}{\mathrm{~d} t}=4 \pi r_{b}^{2} \frac{K_{D_{1}}}{K_{D_{2}}} K_{1}\left(q_{e}-q\right) \mathrm{e}^{\left(K_{D_{2}}-K_{D_{1}}\right) t}
$$

The variation of the number of adsorbed moles produced with time was converted into the rate of change of adsorbed ion concentration per unit resin mass $\left(\frac{\partial q}{\partial t}\right)$ giving the following differential relation $[3,5]$ :

$$
\frac{\partial q}{\partial t}=K_{g_{r}} \frac{K_{D_{1}}}{K_{D_{2}}}\left(q_{e}-q\right) \mathrm{e}^{\left(K_{D_{2}}-K_{D_{1}}\right) t}
$$

where $K_{g_{r}}$ is the resin-specific reaction rate parameter in $\mathrm{s}^{-1}$.

According to the boundary conditions of a moving bed-type reactor $(q=0$ at $t=0)$ the above equation can be integrated giving the following reaction [3]:

$$
\ln (1-X(t))=-K_{g_{r}} \frac{K_{D_{1}}}{K_{D_{2}}} \frac{1}{\left(K_{D_{1}}-K_{D_{2}}\right)}\left[1-\mathrm{e}^{-\left(K_{D_{1}}-K_{D_{2}}\right) t}\right]
$$

However, in this type of reactor (moving bed reactor), the concentration of reactant and product varies with position. Hence, the properties at any height in the bed do not change with time. Figure 1 is a schematic representation of the model considered for this analysis. Under these conditions the residence time is the same for all resin particles. It is related to an elemental height of the reactor length, $\Delta z$, through the following expression:

$$
\Delta t=\frac{\text { volume of particles }}{\text { volumetric flow rate of particle }} .
$$

Accordingly,

$$
\Delta t=\frac{{ }_{\mathrm{Ac}}(\Delta z)\left(\varepsilon_{s}\right)}{\text { mass flow rate } / \rho_{p}}
$$

where $\varepsilon_{s}$ is the fractional holdup of solids (fraction of 


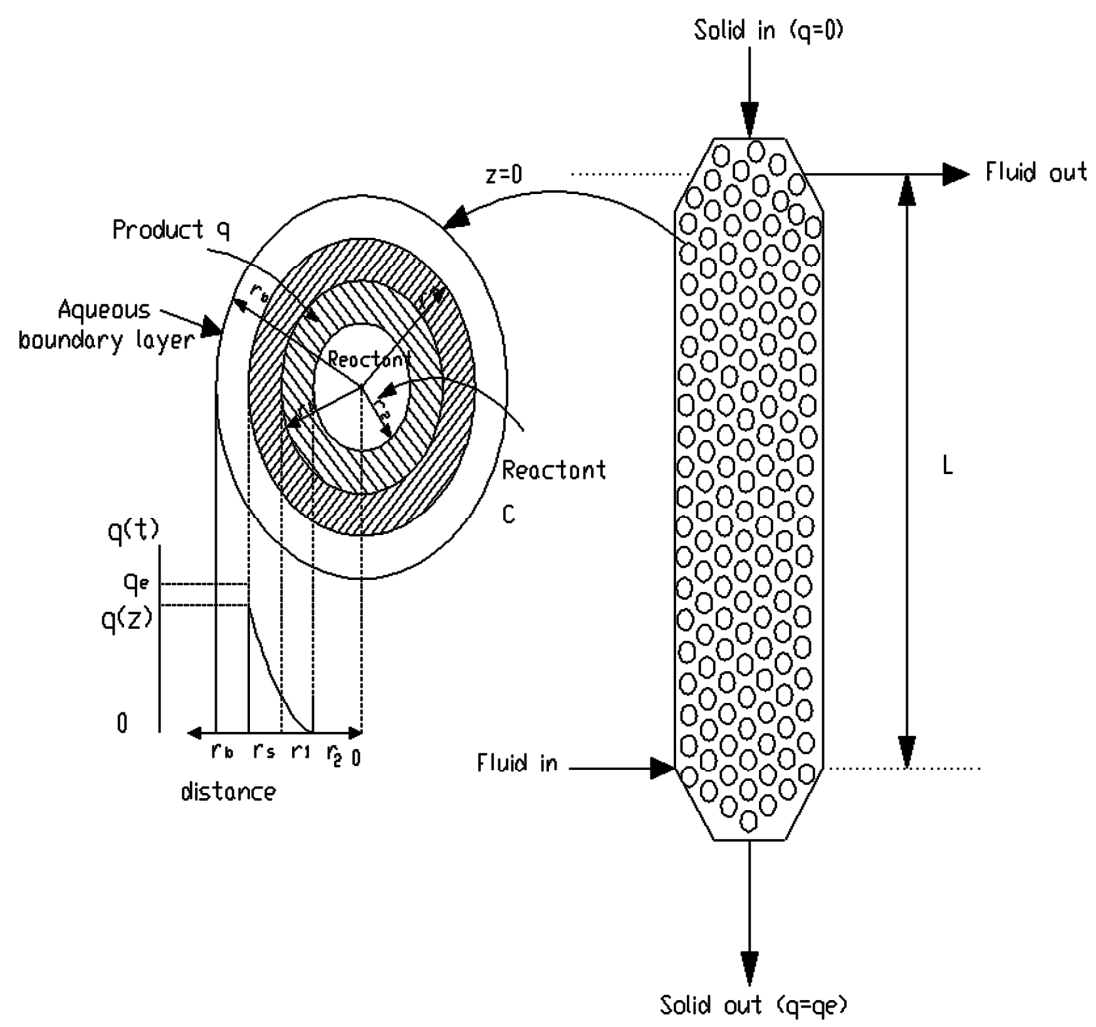

Figure 1. Schematic representation of the model development.

reactor volume occupied by solids), Ac is the cross-sectional area of resin column, and $\rho_{p}$ is the density of the resin and $z$ is the vertical distance of reactor length starting from the solid entrance.

Thus

$$
\mathrm{d} t=\frac{\varepsilon_{s} \rho_{p}}{G_{s}} \mathrm{~d} z
$$

where $G_{s}$ is the superficial mass velocity of solids at $z$, $\mathrm{kg} /\left(\mathrm{m}^{2} \cdot \mathrm{s}\right)$. The relation between the reactor height and the time is thus linear.

Transforming thus $\frac{\partial q}{\partial t}$ to a differential of $\frac{\partial q}{\partial z}$ by multiplying the former by $\frac{\partial t}{\partial z}$, considering Eq.6 and $x=\frac{q}{q_{e}}$ then the following equation could be obtained:

$$
\frac{\partial x}{\partial z}=\frac{\varepsilon_{s} \rho_{p}}{G_{s}}(1-x)\left[K_{g_{r}} \frac{K_{D_{1}}}{K_{D_{2}}}+\left(K_{D_{1}}-K_{D_{2}}\right) \ln (1-x)\right] \text { (10) }
$$

To estimate the required reactor height that yields a conversion of $x L$ the above equation can be written in the following limited integration form:

$$
\int_{0}^{L} \mathrm{~d} z=\int_{0}^{x L} \frac{\mathrm{d} x}{f(x)}
$$

Integrating this equation by considering the boundary conditions that $x=0$ at $z=0$ and $z=L$ at $x=x L$ the following equation could be obtained:

$$
L=\frac{-v}{\Delta K_{D}} \ln \left\{1+\frac{r_{K_{D}} \cdot \Delta K_{D}}{K_{g r}} \ln \left(1-x_{L}\right)\right\}
$$

where $v$ is the "relative resin velocity factor" $(\mathrm{m} / \mathrm{s})$ which is the linear velocity of the resin particles inside the reactor related to the fraction of reactor occupied by resins and equal $\frac{G_{s}}{\varepsilon_{s} \rho_{p}}$.

The diffusion parameter difference $\left(\Delta K_{D}\right)$ is the difference between external and internal diffusion parameters and equals $\left(K_{D_{1}}-K_{D_{2}}\right)$. The diffusion parameter ratio, $\left(r K_{D}\right)$, gives the ratio of internal to external diffusion parameters.

\section{THEORETICAL STUDY}

The model parameters $K_{g_{r}}, K_{D_{1}}$ and $K_{D_{2}}$ indicate whether the process is controlled by chemical reaction, by external, or internal diffusion $[3,5]$. The rate-controlling mechanism can be the diffusion through the aqueous boundary layer to the outermost resin layer (external diffusion) or diffusion inside the particle (internal diffusion). The resin ion-exchange processes are normally considered to be diffusion controlled and not reaction 
controlled [1-5]. When $\left(r K_{D}\right)$ ratio is high, the internal diffusion dominates and is the rate determining step so that $K_{g r}>K_{D_{1}}>K_{D_{2}}$.

The same approach can be applied for other types of control. It should be noted that this ratio is constant for the same reaction condition; i.e. the same solution, the same solid reactant, etc. Diffusion easiness might vary by varying the process condition.

\subsection{Effect of Relative Resin Velocity Factor}

The value of $v$ may be increased by either increasing the superficial resin velocity; i.e. the amount of resin flowing per unit cross sectional area per unit time, or by either decreasing the resin density or the fractional holdup of solids in the reactor. This in turn means either higher resin velocity (i.e. smaller contact time between solute and resin) or the presence of fewer resin particles in the column in a specific time so that less ions will be adsorbed on the resin surface. This is shown in Figure 2 as the conversion extent decreases with increasing the relative resin velocity factor, which in turn requires larger column height. For example at a four-meter column height the estimated percentage conversion reached with a relative resin velocity factor of $7.1 \times 10^{-3} \mathrm{~m} / \mathrm{s}$ is $33.4 \%$, while a ten-time higher velocity factor yields a low conversion of only $4.2 \%$. Increasing the factor ten times more gives an even much lower conversion of $0.43 \%$.

It is to be noted that the residence time of the resins in the reactor is inversely proportional to the relative resin velocity factor so that an increase in the factor causes a reduction in the residence time; i.e. less contact time between the resin particle and the solute ions. This negatively affects the adsorption of ions on the resin particles.

\subsection{Effect of Diffusion Parameter Difference}

Figure 3 shows that increasing the diffusion parameter difference, $\left(\Delta K_{D}\right)$, reduces the conversion extent and a longer reactor is required. With a larger difference lower adsorption is obtained at the same bed height. However, when the variation of this difference is maintained within low enough values the effect is minimized. This observation is similar to that obtained with a fixed bed. For example at a reactor height of $4 \mathrm{~m}$ the percentage conversion obtained with a difference of $2 \times 10^{-3}$ is $22.8 \%$. Lowering the difference by a tenth $\left(2 \times 10^{-4}\right)$ increases the conversion to $33.4 \%$. A further reduction of the difference to $2 \times 10^{-5}$ gives a smaller increment of the adsorption extent to a value of $34.8 \%$. If the reactor height is increased to 1.5 the value $(6 \mathrm{~m})$ the conversion increases to $44.7 \%$ with a difference of $2 \times 10^{-4}$. A reduction of the difference by a tenth slightly increases the conversion to $47.2 \%$ whereas a further increase of the former value by a tenfold $\left(2 \times 10^{-3}\right)$ leads to a significantly lower conversion of $26.8 \%$. This observation contradicts the findings of a former study in a fixed bed reactor as larger diffusion difference offered higher adsorption [5]. Accordingly, in a moving bed reactor the difference between external and internal diffusion parameters should thus be kept as small as possible for effective adsorption and practical reactor height. This difference can be increased by either increasing only the value of external diffusion parameter or increasing both internal and external diffusion parameters with the same proportion.

\subsection{Effect of Diffusion Parameter Ratio}

Increasing the ratio of the diffusion parameters $\left(r_{K_{D}}\right)$

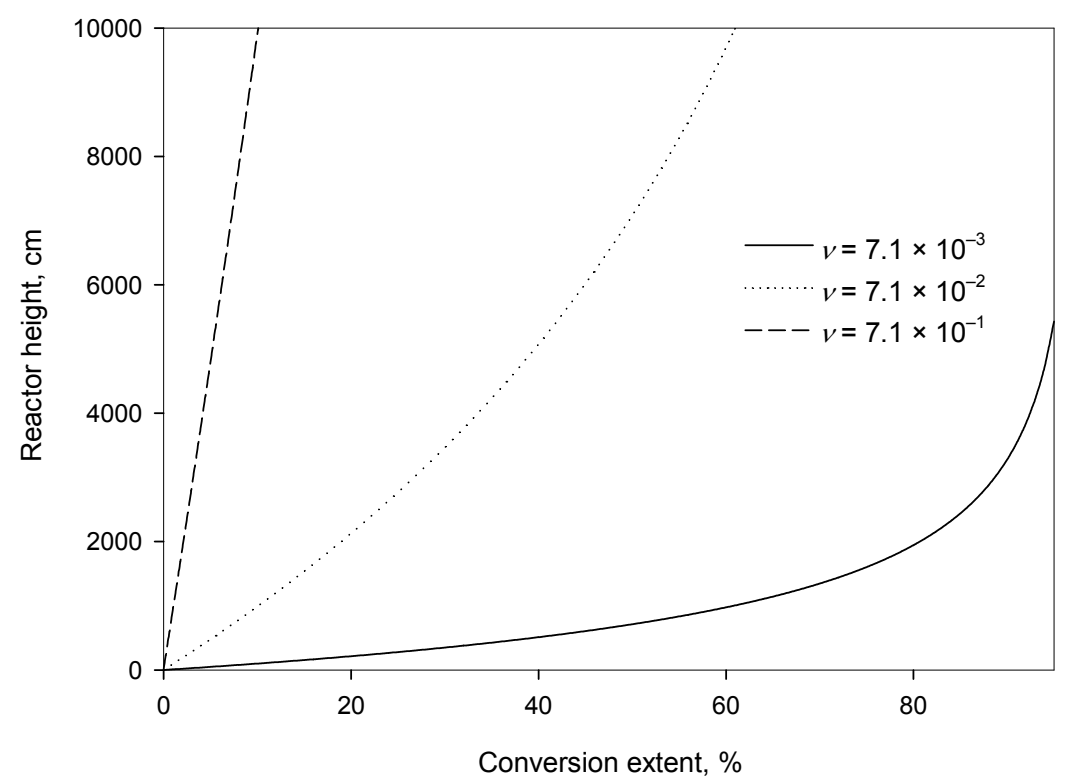

Figure 2. The effect of relative resin velocity factor. 
has the same effect as increasing the difference of diffusion parameters, as the adsorption efficiency decreases and an appreciable increase in the reactor height is needed. This is shown in Figure 4, where for example at a 4-meter height the conversion increases nearly ten times by reducing the ratio by ten folds. With a ratio of 75 the conversion is only $0.4 \%$ while it is $4 \%$ with a ratio of 7.5. At a ratio of 0.75 the conversion is much higher (33.4\%). These observations are again contradicting to those obtained in a fixed bed reactor [5] as a larger ratio was found to increase the column efficiency and the adsorbate ions get adsorbed at a shorter distance.

\subsection{Effect of Resin-Specific Reaction Rate Parameter}

The resin-specific reaction rate parameter can be largely increased by using smaller resin particles [2]. Figure 5 shows that increasing the resin-specific reaction rate parameter largely increases the conversion extent and reduces the required reactor height. At a short column depth of only $25 \mathrm{~cm}$ the conversion is low $(2.6 \%)$ with a $K_{g_{r}}$ value of $6 \times 10^{-4}$. However, increasing the $K_{g_{r}}$ value ten times $\left(6 \times 10^{-3}\right)$ greatly increases the conversion to $24 \%$. A further similar increase of the $K_{g_{r}}$. value to $6 \times 10^{-2}$ gives a conversion extent as high as

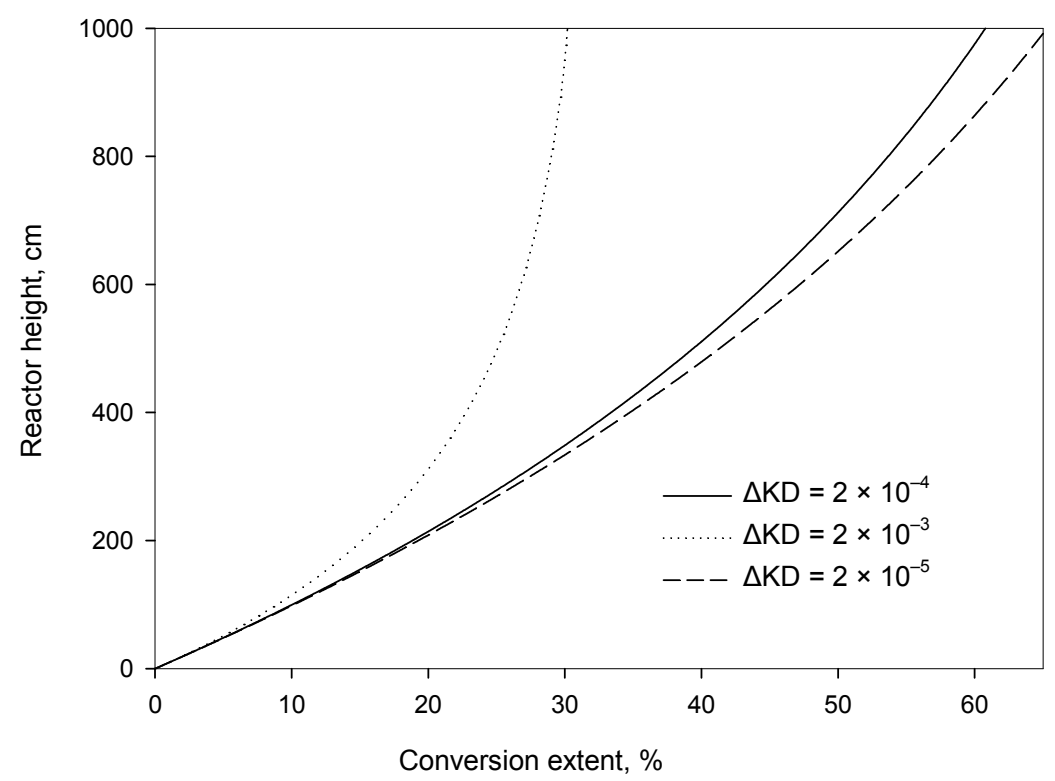

Figure 3. The effect of diffusion parameter difference.

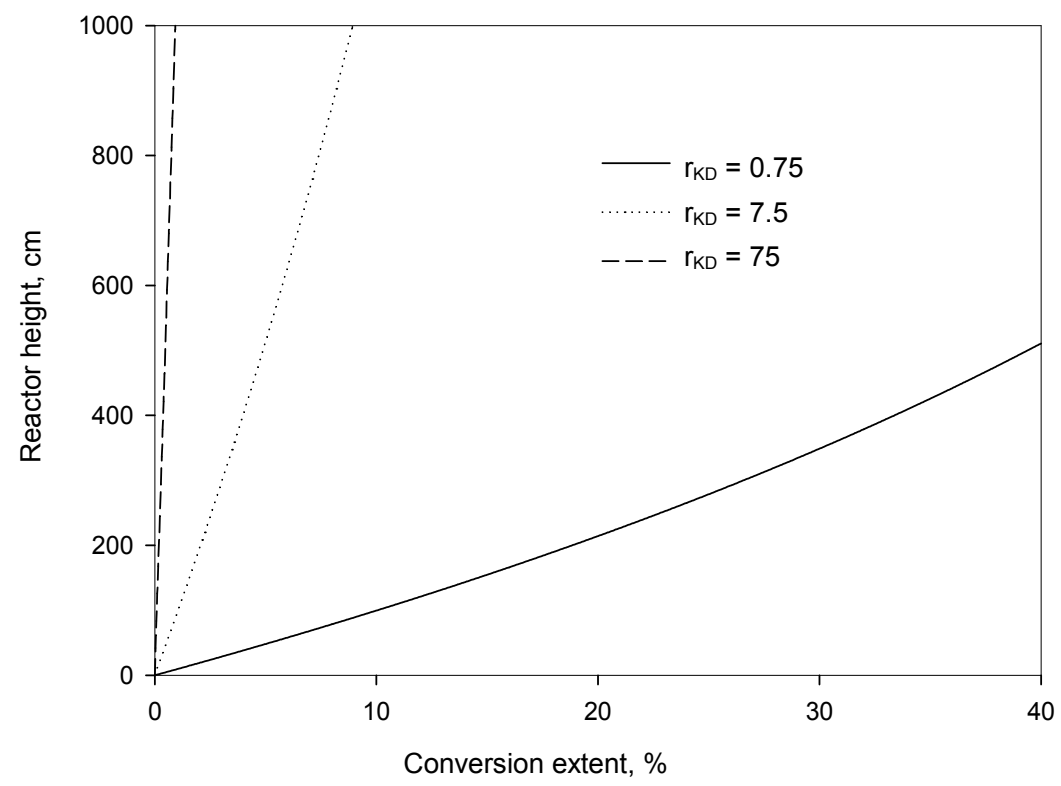

Figure 4. The Effect of diffusion parameter ratio. 
93.8\%. A slight variation of the $K_{g_{r}}$ value provides thus an effective impact on the conversion extent, which can be reasonably understood as this parameter includes the reaction rate constant that is responsible for the speed of reaction. These findings agree with those obtained by Othman et al. [1-5].

\section{EXPERIMENTAL STUDY}

Table 1 includes the regression analysis of Eq.6 for series of experiments together with the estimated relative values of $K_{D_{1}}, K_{D_{2}}$ and $K_{g_{r}}$ for the current model concerning two different concentrations of a single metal ion solution; high $\left(1 \times 10^{-2} \mathrm{M}\right)$ and low $\left(1 \times 10^{-4} \mathrm{M}\right)$ concentration. It is observed for the three metal ions that the chemical reaction is controlling for both concentrations as $K_{g r} \ll K_{D_{1}}$. These results can be attributed to the applied experimental conditions where shallow-bed technique on a micro scale is used. In this technique an aqueous metal solution is passed at a high flow-rate through a thin layer of resin beads in a column. The objective of this procedure is to avoid the formation of a concentration gradient along the bed, either in the resin or in the solution. Thus, the solution composition remains practically constant throughout the experiment. Accordingly, the shallow bed technique simulates the operation conditions of industrial moving beds.

\subsection{Sorption Kinetics at High Concentration}

This series of experiments are run at a relatively high concentration $\left(1 \times 10^{-2} \mathrm{M}\right)$ with the purpose of promoting internal diffusion control. The first hour of the process is studied in this experiment. The correlations indicate a good fit for Eq.12. A comparison of the model parameters shows that there are significant differences in diffusivity for the three metal ions. For the high concentration $\left(1 \times 10^{-2} \mathrm{M}\right)$, the relative order of diffusivity in

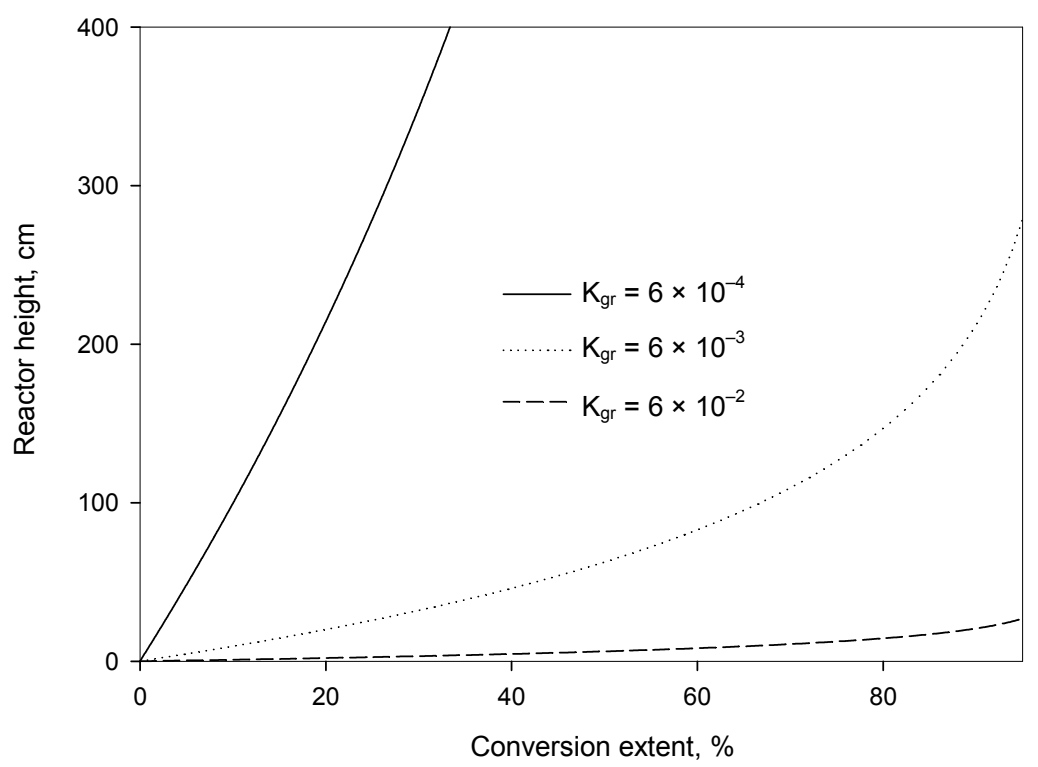

Figure 5. The Effect of resin-specific reaction rate parameter.

Table 1. The physical parameters for the three cations in high and low solution concentrations.

(a) High Concentration $1 \times 10^{-2} \mathrm{M}$

\begin{tabular}{ccccccc}
\hline Ion & $K_{g r}$ & $K_{D 1}$ & $K_{D 2}$ & $\Delta K_{D}$ & $r_{K_{D}}$ & $R^{2}$ \\
\hline $\mathrm{Zn}^{2+}$ & $8.02 \times 10^{-5}$ & $1.33 \times 10^{-3}$ & $2.54 \times 10^{-4}$ & $7.8 \times 10^{-4}$ & 4.1 & 0.96 \\
$\mathrm{Cu}^{2+}$ & $4.30 \times 10^{-5}$ & $1.24 \times 10^{-3}$ & $1.91 \times 10^{-4}$ & $1.1 \times 10^{-3}$ & 6.5 & 0.95 \\
$\mathrm{Cd}^{2+}$ & $5.70 \times 10^{-5}$ & $8.99 \times 10^{-4}$ & $1.93 \times 10^{-4}$ & $7.0 \times 10^{-3}$ & 4.7 & 0.97 \\
\hline
\end{tabular}

(b) Low Concentration $1 \times 10^{-4} \mathrm{M}$

\begin{tabular}{ccccccc}
\hline Ion & $K g r$ & $K_{D 1}$ & $K_{D 2}$ & $\Delta K_{D}$ & $r_{K_{D}}$ & $R^{2}$ \\
\hline $\mathrm{Zn}^{2+}$ & $1.0 \times 10^{-4}$ & $3.75 \times 10^{-5}$ & $3.64 \times 10^{-5}$ & $7.8 \times 10^{-4}$ & 1.0 & 0.96 \\
$\mathrm{Cu}^{2+}$ & $1.03 \times 10^{-5}$ & $5.91 \times 10^{-4}$ & $5.46 \times 10^{-4}$ & $1.0 \times 10^{-4}$ & 1.1 & 0.97 \\
$\mathrm{Cd}^{2+}$ & $5.82 \times 10^{-6}$ & $4.52 \times 10^{-4}$ & $3.93 \times 10^{-4}$ & $7.0 \times 10^{-3}$ & 1.2 & 0.97 \\
\hline
\end{tabular}


the solution is: $\mathrm{Zn}^{2+}>\mathrm{Cu}^{2+}>\mathrm{Cd}^{2+}$. Accordingly, $\mathrm{Cd}^{2+}$ solution has the highest diffusion parameter difference, $\left(\Delta K_{D}\right)$, followed with $\mathrm{Cu}^{2+}$ followed with $\mathrm{Zn}^{2+}$, which has the lowest difference as well as the lowest diffusion parameter ratio.

Figure 6 shows the results of the extraction kinetics of $\mathrm{Zn}^{2+}, \mathrm{Cu}^{2+}$ and $\mathrm{Cd}^{2+}$ from single element solutions in the form of the suggested model defined by Eq.12. The theoretical results give satisfactory agreement to those obtained experimentally. As the resin-specific reaction rate parameter is the most affecting in the adsorption extent, as shown in the theoretical study, $\mathrm{Zn}^{2+}$ yields the highest conversion extent followed by $\mathrm{Cd}^{2+}$ followed by $\mathrm{Cu}^{2+}$ although the corresponding values differ only slightly from each other. This observation fits well with the decreasing tendency of the $K_{g r}$ values, which again supports the findings that $K_{g r}$ plays a significant effective role in the conversion extent (Figure 5).

\subsection{Sorption Kinetics at Low Concentration}

For $\mathrm{Zn}^{2+}$ and $\mathrm{Cu}^{2+}$ solutions the $K_{D}$ values are appre-

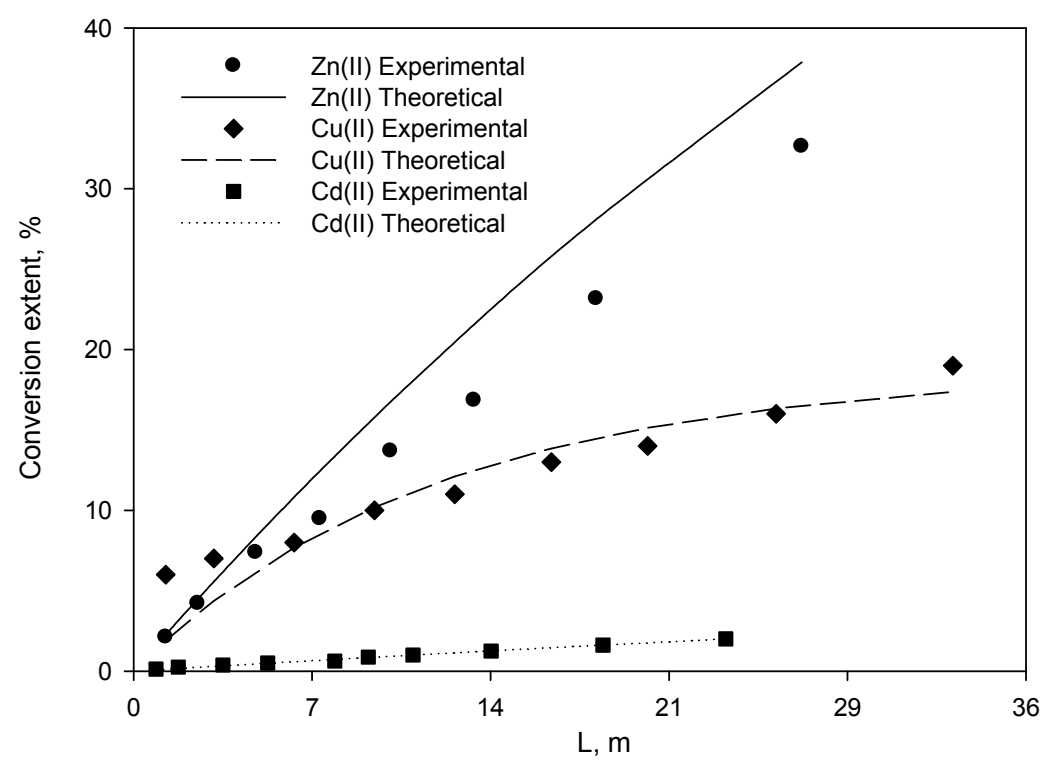

(a)

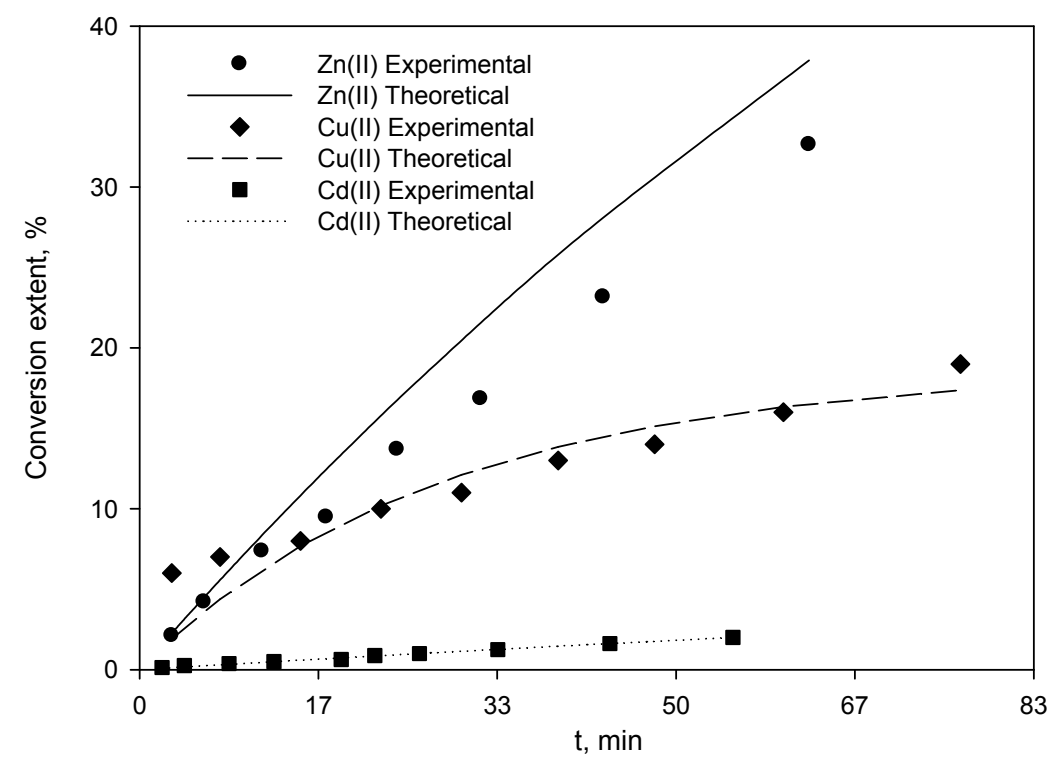

(b)

Figure 6. Comparison between the conversion extents obtained for the three low concentrated $\left(1 \times 10^{-4} \mathrm{M}\right)$ metal ion solutions with respect to (a) reactor height and (b) time. 
ciably lower than the corresponding ones for high concentrations indicating poorer adsorption in both the solution and resin particles due to the lower concentration. However, the corresponding diffusion parameter differences in low as well as high concentrations are the same for the three solutions indicating that the $K_{D}$ values decrease with the same amount. On the other hand, the diffusion parameter ratios are nearly the same for the three solutions. For $\mathrm{Cu}^{2+}$ and $\mathrm{Cd}^{2+}$ solutions the $K_{g r}$ values are significantly lower than the corresponding ones at high concentration. However, the $K_{g r}$ value for the $\mathrm{Zn}$ solution is higher than the corresponding one at high solution concentration.
In the current case $K_{D_{1}}$ is bigger than $K_{D_{2}}$ indicating a much smaller difference than that observed at higher concentration indicating that both external and internal diffusion find comparable resistance. The $K_{g r}$ values for $\mathrm{Cu}^{2+}$ and $\mathrm{Cd}^{2+}$ are found to be significantly smaller than both $K_{D_{1}}$ and $K_{D_{2}}$ indicating a chemical reaction control. Figure 7 shows the conversion extent $(x)$ as a function of contact time as yielded experimentally and theoretically at low concentration of the three metal ions $\left(\mathrm{Zn}^{2+}, \mathrm{Cu}^{2+}\right.$ and $\left.\mathrm{Cd}^{2+}\right)$. The figure shows that $\mathrm{Zn}^{2+}$ yields the highest conversion extent followed by $\mathrm{Cu}^{2+}$ followed by $\mathrm{Cd}^{2+}$. This is again in full agreement with the incremental trend of the $K_{g r}$ values of the corre-

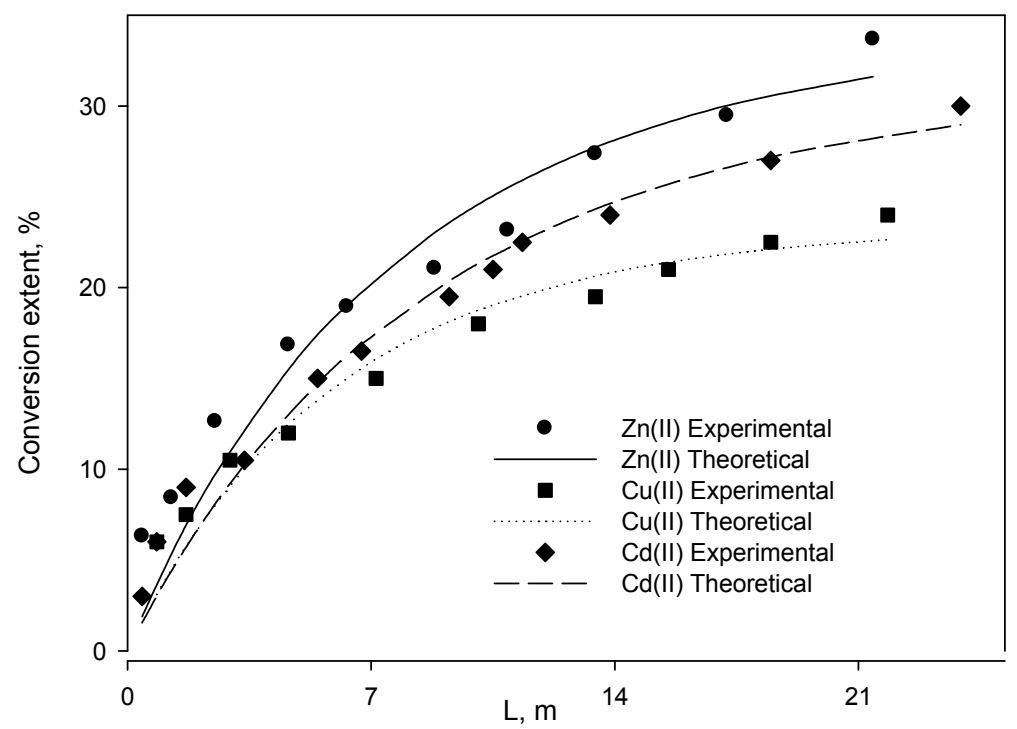

(a)

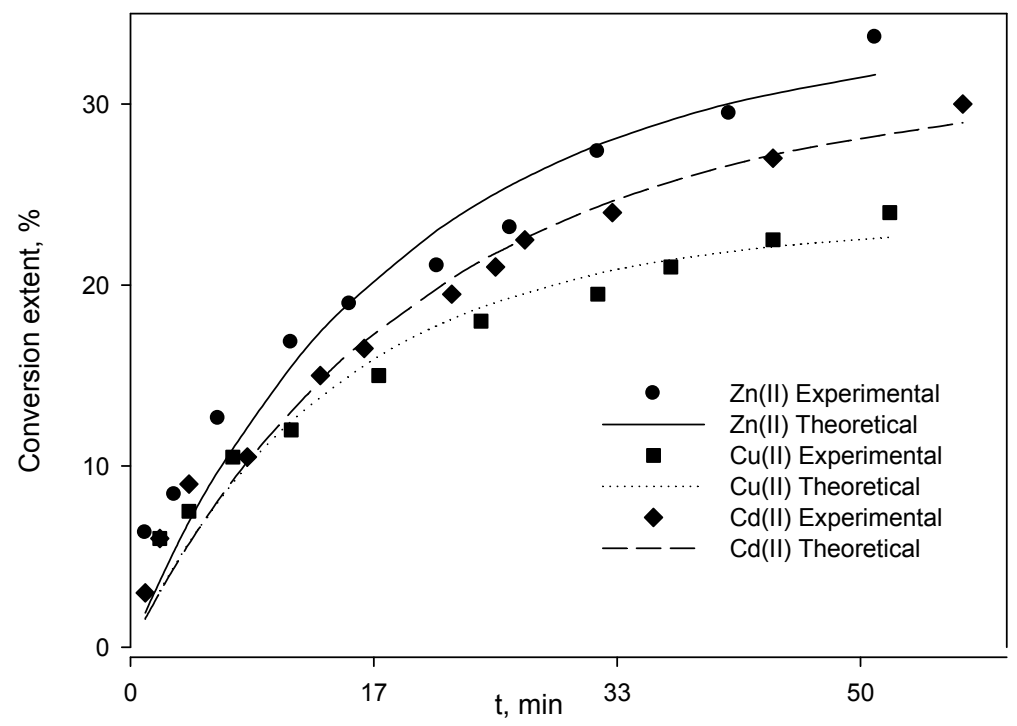

(b)

Figure 7. Comparison between the conversion extents obtained for the three highly concentrated $\left(1 \times 10^{-2} \mathrm{M}\right)$ metal ion solutions with respect to (a) reactor height and (b) time. 
sponding salts.

It is observed from Table 1 that the highest $K_{D_{1}}$ and $K_{D_{2}}$ values are provided with $\mathrm{Zn}^{2+}$ ions in the highly tested solution concentration whereas $\mathrm{Cd}^{2+}$ ions offer the least $K_{D 1}$ value. This is nearly the same for $K_{D_{2}}$ values since $\mathrm{Cd}^{2+}$ and $\mathrm{Cu}^{2+}$ ions have almost the same $K_{D_{2}}$ values. However, the high ranking of $\mathrm{Zn}^{2+}$ ions turns to be opposite in case of low solution concentration as $\mathrm{Zn}^{2+}$ yields the least $K_{D_{1}}$ and $K_{D_{2}}$ values, whereas $\mathrm{Cu}^{2+}$ ions provide the highest diffusion parameter values.

In both solution concentrations $\mathrm{Zn}^{2+}$ ions yield the lowest $\left(r_{K_{D}}\right)$ and $\left(\Delta K_{D}\right)$ values and the highest $K_{g r}$ values. It is not worthy that the $\left(r_{K_{D}}\right)$ values in case of low concentrations are almost the same around unity with a slight variation while they differ appreciably in case of high concentration. It is formerly stated that a high ratio indicate an internal diffusion control; which is in good agreement with the obtained experimental data as in a high concentrated solution the internal diffusion provides a much higher resistance compared to external diffusion. However, this cannot exclude the effect of chemical reaction which, depending on its value, is the most pronouncing and is thus the controlling step in both solution concentrations. Therefore, the order of the experimentally obtained values of adsorption extent follows the ranking order of the $K_{g r}$ values.

\section{CONCLUSION}

A mathematical model is proposed to simulate the adsorption of three metal ions $\left(\mathrm{Zn}^{2+}, \mathrm{Cu}^{2+}\right.$, and $\left.\mathrm{Cd}^{2+}\right)$ from nitrate solutions using two different concentrations $\left(10^{-2}\right.$ and $10^{-4} \mathrm{M}$ ) with XAD2-HL impregnated resins. Adsorption is done via a counter-flow moving bed reactor. The model takes into consideration the internal and external diffusion effects as well as the effect of chemical reaction. The effect of these parameters beside other suggested ones on the adsorption extent has been investigated. The model allows the calculation of the required reactor height against the conversion extent. The process is found to be controlled by chemical reactions as a high solution velocity is utilized to simulate the operation conditions of industrial moving beds and to avoid the formation of a concentration gradient along the bed, either in the resin or in the solution. Thus, the solution composition remains practically constant throughout the experiment. Accordingly, the test conditions are directed towards the individual values of $K_{g r}$ that are much less than the corresponding values of $K_{D_{1}}$ or $K_{D_{2}}$.

\section{REFERENCES}

[1] Othman, S.H., Shabaan, M., Demerdash, M. and Saleh, M.M. (2009) Experimental and theoretical investigation of sorption kinetics of beryllium on Amberlite-IR-120 sorbent. Journal of Nuclear Materials. 392, 427-433. doi:10.1016/j.jnucmat.2009.04.001

[2] Othman, S.H., Sohsah, M.A., Ghoneim, M.M., Sokkar, H.H., Badawey, S.M. and El Anadouli, B.E. (2006) Mathematical simulation of hazardous ion retention from radioactive waste in a fixed bed reactor. Industrial \& Engineering Chemistry Research, 45, 2808-2817. doi:10.1021/ie0507676

[3] Othman, S.H., Ali, A.H., Mansour, N.A. and El Anadouli, B.E. (2012) The effect of external and internal diffusion on the sorption of radioactive ions by reactive cloth filter, part I. Journal of Radioanalytical and Nuclear Chemistry, 291, 685-698. doi:10.1007/s10967-011-1421-3

[4] Othman, S.H., Saleh, M.M., Demerdash, M. and El Anadouli, B.E. (2010) Mathematical model: Retention of beryllium on flow-through fixed bed reactor of Amb-IR-120. Chemical Engineering Journal, 156, 157-164. doi:10.1016/j.cej.2009.09.018

[5] Ali, A.H. and Othman, S.H. (2011) A physico-chemical parametric study on the retention of radioactive ions in a fixed bed reactor. Chemical Engineering Journal, 178, 375-383. doi:10.1016/j.cej.2011.10.030

[6] Flett, D.S. (1977) Resin impregnates: The current position. Chemical Industries, 641-646.

[7] Tavlaride, L.L., Bae, J.H. and Lee C.K. (1987) Solvent extraction, membranes, and ion exchange in hydrometallurgical dilute metals separation. Separation Science and Technology, 22, 581-617. doi:10.1080/01496398708068970

[8] Warshawsky, A. (1981) Extraction with solvent-impregnated resins. Ion Exchange and Solvent Extraction, 8, 229-310.

[9] Cortina, J.L., Miralles, N., Sastre, A., Aguilar, M., Profumo, A. and M. Pesavento (1993) Solvent impregnated resins containing di(2,4,4-trimethylpentyl)phosphinic acid. I. Comparative study of di(2,4,4-trimethylpentyl)phosphinic acid adsorbed on Amberlite XAD-2 and dissolved in toluene. Reactive Polymers, 21, 89-101.

[10] Cortina, J.L., Miralles, N., Aguilar, M. and Sastre, A.M. (1994) Solvent impregnated resins containing di(2-ethylhexyl)phosphoric acid. I. Preparation and study of the retention and distribution of the extractant on the resin. Solvent Extraction and Ion Exchange, 12, 349-369. doi:10.1080/07366299408918214

[11] Cortina, J.L., Miralles, N., Sastre, A., Aguilar, M., Profumo, A. and Pesavento M. (1993) Solvent impregnated resins containing di(2,4,4 trimethylpentyl)phosphinic acid. II. Study of the distribution equilibria of $\mathrm{Zn}, \mathrm{Cu}$ and $\mathrm{Cd}$. React. Polymer, 21, 103-116. doi:10.1016/0923-1137(93)90057-M

[12] Cortina, J.L., Miralles, N., Aguilar, M. and Warshawsky, A. (1995) Solid-liquid distribution studies of divalent metals from nitrate media using impregnated resins containing a bifunctional organophosphorous extractant (o-methyldihexylphosphine oxide o'-hexyl-2-ethylphosphoric acid). Reactive and Functional Polymers, 27, 61-73. doi:10.1016/1381-5148(95)00035-E

[13] Helfferich, F. (1962) Ion exchange. MaGraw-Hill, New 
York, 250-266.

[14] Liberti, L. and Passino, R. (1977) Ion-exchange and solvent extraction. Marcel Dekker, Inc., New York, 3.

[15] Juang, R.S. and Lin H.C. (1995) Metal sorption with

\section{LIST OF SYMBOLS}

$A_{c}$ : Cross-sectional area of resin column $\left(\mathrm{m}^{2}\right)$;

$b$ : Number of active sites in a unit surface area $\left(\mathrm{mole} / \mathrm{m}^{2}\right)$;

$G_{s}:$ Superficial mass velocity of resins $\left(\mathrm{kg} /\left(\mathrm{m}^{2} \cdot \mathrm{s}\right)\right)$;

$K_{1}$ : Chemical reaction rate parameter $\left(\mathrm{kg} /\left(\mathrm{m}^{2} \cdot \mathrm{s}\right)\right)$;

$K_{D 1}$ : External diffusion parameter $\left(\mathrm{s}^{-1}\right)$;

$K_{D 2}$ : Internal diffusion parameter $\left(\mathrm{s}^{-1}\right)$;

$K_{g r}:$ Resin-specific reaction rate parameter $\left(\mathrm{s}^{-1}\right)$;

$L$ : Reactor height (m);

$N$ : Number of moles adsorbed per particle per unit time (moles/s);

$q$ : Adsorbed metal ion concentration per unit resin mass (mole $/ \mathrm{kg})$;

$q_{e}$ : Equilibrium concentration of adsorbed metal ions extractant-impregnated macro-porous resins. 2. Chemical reaction and particle diffusion kinetics. Journal of Chemical Technology \& Biotechnology, 62, 141-147. doi: $10.1002 /$ jetb. 280620205

per unit resin mass (mole/kg);

$r_{b}$ : Radius of boundary layer $(\mathrm{m})$;

$r_{K D}$ : Diffusion parameter ratio, dimensionless;

$t$ : Time (s);

$x$ : Fractional adsorption extent, dimensionless;

$z$ : Fractional column height (vertical distance in $\mathrm{m}$ of reactor length starting from the solid entrance).

\section{GREEK LETTERS}

$\Delta K_{D}$ : Diffusion parameter difference $\left(\mathrm{s}^{-1}\right)$;

$\rho:$ Resin density $\left(\mathrm{kg} / \mathrm{m}^{3}\right)$;

$\varepsilon_{s}$ : Fractional holdup of resins in column, dimensionless;

$v$ : Relative resin velocity factor $(\mathrm{m} / \mathrm{s})$. 